\title{
Condensation Targeter II: Modelling surface relative humidity to predict mould growth in dwellings
}

T Oreszczyn $\uparrow$ BSc PhD MinstE MCIBSE CEng and S E C Pretloveł BSc(Hons) MSc(Arch) MBEng MCIOB

$\uparrow$ The Bartlett School of Graduate Studies, University College London, Gower Street, London WC1E 6BT \$ School of Construction, South Bank University, 202 Wandsworth Road, London, SW8 2JZ

\section{Summary}

Condensation and mould growth is reported as being a problem in an estimated 4.2 million dwellings in England resulting in poor occupant health and substantial damage to the building fabric. This paper examines the development of an algorithm, Condensation Targeter, to predict the internal surface relative humidity and risk of mould growth in dwellings. The impact of cold bridging, seasonal variations, variable moisture production and hygroscopic materials are reviewed (but not interstitial condensation) and a comparison between modelled and measured data for 36 dwellings carried out. Results indicate that a steady-state model utilising Bredem- 8 to predict internal temperatures and Loudon's condensation model to predict moisture shows good $( \pm 10 \%)$ agreement with monitored data. A model sensitivity study shows that variations in occupant heating and density can be as, or even more, important in determining mould growth than ventilation. 


\section{List of symbols}

C Rate of moisture input $\left(\mathrm{kg} \mathrm{day}^{-1}\right)$

$G \quad$ Rate of moisture input $\left(\mathrm{kg} \mathrm{h}^{-1}\right)$

$n \quad$ Ventilation rate $\left(\mathrm{ac} \mathrm{h}^{-1}\right)$

$p \quad$ Vapour pressure $(\mathrm{kPa})$

$R \quad$ Thermal resistance $\left(\mathrm{m}^{2} \mathrm{~K} \mathrm{~W}^{-1}\right)$

$T \quad$ Temperature $\left({ }^{\circ} \mathrm{C}\right)$

TDR Temperature Difference Ratio

$U \quad$ U-value $\left(\mathrm{Wm}^{-2} \mathrm{~K}^{-1}\right)$

$v \quad$ Volume of the room $\left(\mathrm{m}^{3}\right)$

$\psi \quad$ Vapour content of the air $\left(\mathrm{kg} \mathrm{kg}^{-1}\right)$

$\psi_{s v p} \quad$ Vapour content of the air at saturation vapour pressure $\left(\mathrm{kg} \mathrm{kg}^{-1}\right)$

$\alpha, \beta \quad$ Moisture admittance coefficients

$\rho \quad$ Density of air $\left(\mathrm{kg} \mathrm{m}^{-3}\right)$

\section{Subscripts}

$i \quad$ inside

$o \quad$ outside

$s \quad$ internal surface 


\section{$1 \quad$ Introduction}

Condensation and mould growth remains a substantial problem in an estimated $22 \%$ of English housing ${ }^{(1)}$. Similar levels are also reported in other Northern European countries $^{(2)}$. There is now increasing evidence that living in such damp dwellings can have a significant impact on health ${ }^{(3)(4)}$. Designers of new dwellings and those refurbishing existing properties require some mechanism for assessing the impact of design changes on the risk of mould growth. The problems of mould growth in dwellings are not purely technical but are related to the way that dwellings are used, which in turn is linked to the price of fuel, changes in lifestyle and occupant densities. Tools are required to assess these issues as well as the impact of technical changes to the fabric and ventilation of a building.

Various moisture models, ranging from simple steady-state calculations to two and three-dimensional models incorporating different hygroscopic properties have been developed $^{(5)}$ and some moisture models have been integrated with transient thermal models $^{(6)}$. All such models can play a significant role in research. However, at present only simpler techniques are useful for design and policy making since much of the detail required for the more complex models is often not available at the crucial stages of design. Therefore, the accuracy of simple models needs to be assessed. One such simple model (Condensation Targeter I) was proposed by Boyd et $\mathrm{al}^{(7)}$ and implemented commercially as Targeter ${ }^{(8)}$ and more recently as Evaluator ${ }^{(36)}$. This program has been used by local authorities and consultants and has been used as evidence in court cases ${ }^{(9)}$. The original research indicated the limitations of such a simple model ${ }^{(7)}$ and also stated that any such model required some validation. Given 
the demand for a model, this paper examines the limitations of Condensation Targeter, proposes developments to the model (Condensation Targeter II) and compares model predictions to monitored relative humidities in $36 \mathrm{UK}$ dwellings. This paper investigates the occurrence of surface mould growth and does not investigate the occurrence of interstitial condensation.

\section{Condensation Targeter}

The Condensation Targeter I algorithm incorporated the energy model, Bredem-5, enhanced by incorporating Loudon's condensation model ${ }^{(27)}$. The objective of this enhanced model was to produce a computer package for use by those responsible for the maintenance and design of housing, predominately for rent, to assess the risk of surface condensation and mould growth. The model takes into account both the dwelling and occupant characteristics and is able to assess the impact of remedial measures, such as draught stripping or central heating, as well as changes in fuel expenditure, occupant density and different patterns of moisture production. The model only deals with the risk of high humidities and condensation at the surface of the building façade as a result of internally generated moisture and does not deal with the problems of interstitial condensation, rising damp or water penetration.

\section{$2.1 \quad$ Limitations}

When Condensation Targeter I was developed in 1987 it was considered to be the most practical solution integrating the existing knowledge. However, the authors were 
aware that the model required validation against measured data and that there were several limitations including the following:

1. The use of mean winter conditions for temperature and moisture levels may not model the most critical conditions. Intermittent heating, changing external climatic conditions and the hygroscopic properties of the building fabric and furnishings may result in conditions suitable for mould growth but not characterised as a problem by examining the mean conditions.

2. The model predicts mean conditions within two zones of the building. Spatial averaging does not account for high condensation risk in specific rooms of a dwelling and at areas of fabric with high local heat loss such as cold bridges.

3. The model assumes a fixed ventilation rate, yet seasonal variations in ventilation may have an impact on the internal moisture content, as may local ventilation such as extract fans.

Research into some of these issues over the last decade means that substantial improvements to the original model can be developed. Figure 1 shows a schematic diagram of Condensation Targeter II incorporating a more detailed monthly thermal, moisture and mould model. These improvements are outlined in detail in the following section.

\section{Condensation Targeter developments}




\subsection{Criteria for mould growth}

Mould requires oxygen, food, spores and water to germinate and grow. However, water availability is the primary factor controlling mould growth in buildings. Spores are always present in the outside and even in the winter concentrations rarely drop below a few hundred spores per cubic metre of air ${ }^{(10)}$. Oxygen is available in buildings and even a small layer of grease, as found on most building surfaces, provides an adequate quantity of food for mould to grow. The availability of moisture is therefore the critical factor. The best information currently available is that a surface surrounded and at equilibrium with a relative humidity greater than $80 \%^{(2)(40)}$ for a prolonged period (a month or longer) is adequate to cause germination and mould to grow on most common building surface materials, such as emulsion coated plaster or wallpaper. However, on hygroscopic materials, such as certain types of leather, mould can grow at relative humidities as low as $73 \%{ }^{(10)}$ whereas non-hygroscopic surfaces such as glass and metals require $100 \%$ relative humidity and condensation to occur.

Different species of mould require different environmental conditions to thrive. The three most common genera of mould found in UK dwellings include Aspergillus, Penecillium and Cladosporium. Two of the most common species, Aspergillus versicolor and Penecillium brevicompactum, require a surface relative humidity of $79 \%$ and $80 \%$ respectively on emulsion painted woodchip wallpaper at a temperature of $18^{\circ} \mathrm{C}^{(11)}$. In the laboratory, Aspergillus repens has been grown at a relative humidity as low as $76 \%{ }^{(6)(11)}$. 
Temperature has a slight effect on mould growth requirements. Generally, within the normal range of temperatures experienced inside dwellings, at lower temperatures mould requires a higher relative humidity to grow. However, this is not true for all types of mould and it should not be assumed that the critical condition is vapour pressure rather than relative humidity.

There is considerable anecdotal evidence that air movement can have an impact on mould growth yet very little scientific data exists. Surfaces behind obstructions and corners are generally the first place for mould to start growing. However, this growth can normally be explained due to the modified heat transfer at these surfaces as a result of the fabric structure and not air movement. For example, the internal heat transfer coefficient on an unobstructed wall can be 4 times higher than that behind furniture where there is no air flow ${ }^{(12)}$. It is worth noting, however, that the vapour transfer coefficient is also related to the heat transfer coefficient by the Lewis relationship and so vapour transfer will also be reduced at such locations.

The majority of studies examining the critical conditions for mould to grow have been undertaken in controlled environmental chambers under steady-state conditions. There is currently little guidance as to the impact of transient conditions on mould growth. If, for example, the surface relative humidity is $90 \%$ for $20 \%$ of the time but the average surface relative humidity is below $80 \%$, this may be sufficient for mould to grow even though the average surface relative humidity indicates that it will not. For this reason, at present, transient models offer little practical advantage in predicting where mould will grow, as it is difficult to interpret the results. 
Condensation Targeter I assumed an airspace (or room) relative humidity of $70 \%$ as the critical condition for mould growth. Condensation Targeter II assumes the critical condition of $80 \%$ at the surfaces of walls, ceilings and floors and $100 \%$ at the glazing. The following section discusses how the surface conditions can be predicted.

\section{$3.2 \quad$ Cold Bridging}

Cold bridging occurs where there are high heat losses through a part of the building fabric. This can be due to either the inappropriate use of materials which have a high thermal conductivity or where heat losses are high due to the geometry of the structure, such as in corners of the building. Significant developments in two and three-dimensional thermal modelling have allowed heat flow in almost any building component to be modelled. Catalogues of typical constructions are now available which indicate the behaviour of cold bridge details ${ }^{(38)}$. Cold bridges are the first place at which mould growth occurs because of their lower temperature and higher surface relative humidity. The severity of a cold bridge can be characterised by the Temperature Difference Ratio (TDR) ${ }^{(14)}$.

$$
T D R=\frac{T_{i}-T_{s}}{T_{i}-T_{o}}
$$

The TDR can be easily calculated for plain surfaces with one-dimensional heat flow using the following equation. 
The higher the TDR the more severe the cold bridge is. Typically, the value of the TDR in most building constructions will vary between 0.0 and 0.3 . A double glazed window will have a plain surface TDR of around 0.3. Any wall surface with a TDR higher than 0.3 will be colder than the glazing and therefore condensation will occur on the wall before the window. For surfaces with a TDR less than 0.3 condensation will occur on the glazing first which will be seen by the occupants who will often be motivated to reduce the airspace relative humidity by increasing ventilation ${ }^{(15)}$. If the condensation occurs on an opaque element it will be largely unseen and the occupants, who are generally insensitive to relative humidity, will not increase the ventilation. The TDR is directly comparable to the Temperature Factor at the internal surface as currently proposed in the draft European standard ${ }^{(16)}$ for the hygrothermal performance of building components and conversion between the two is obtained by subtracting from one.

Under transient conditions the surface temperature will not be accurately predicted by the TDR. However, the TDR is a good representation of the average surface temperature that a construction will experience during transient conditions ${ }^{(37)}$.

Once the internal and external conditions and TDR of a particular construction are known it is possible to identify the mean surface relative humidity and temperature. Also, for a given construction, it is possible to calculate the TDR and predict the maximum airspace relative humidity required to avoid surface mould growth. Figure 2 shows a nomogram of the maximum airspace relative humidity to avoid surface 
relative humidity going above $80 \%$ (the critical figure for mould growth). This clearly shows that the conventional wisdom of maintaining airspace relative humidity below $70 \%$ is only effective for constructions which have a TDR lower than 0.1 . Examples of constructions which have a TDR greater than 0.1 include most windows and doors, solid walls and early cavity walls with $\mathrm{U}$-values greater than $0.8 \mathrm{~W} / \mathrm{m}^{2} \mathrm{~K}$, some of which may require airspace relative humidity to be kept below $60 \%$ to avoid mould growth.

Condensation Targeter II allows the TDR for any part of the structure to be incorporated into the calculation. The TDR is then used to calculate the mean surface relative humidity. For plain constructions the TDR is calculated from the U-value. For more complex geometry constructions a TDR must be entered based on either finite element calculations or published catalogue data.

\subsection{Moisture production}

Moisture production in a dwelling is variable, localised and occupant dependent. The best that any model can hope to achieve is to model a typical occupancy pattern. The model will never predict what a particular occupant will do. BS 5250 gives typical moisture production rates for a variety of different moisture producing household activities. These are, however, dependent on detailed occupancy and prone to change as a result of the introduction of new technologies into the home, such as the increased use of microwave cooking and pre-cooked meals. Although the impact of technological changes can be predicted from theory the most difficult thing to model is how occupants will use any new technology. Therefore, moisture production 
algorithms will always have an empirical nature and should be regularly reviewed. The number of occupants assumed will also depend upon the application of the model. For example, when designing systems for social housing it may be best to assume the permitted maximum number of occupants.

Following the review of literature relating to moisture production ${ }^{(17-22)}$ a new moisture production calculation procedure has been developed. This takes into account the available data on moisture production and enables the calculation of the daily moisture production rate in a dwelling with a minimum number of input parameters. Each of the key factors affecting moisture production are analysed separately and the algorithms used to predict the total moisture production in Condensation Targeter II are listed in Table 1.

Figure 3 shows the typical breakdown of moisture production for a family consisting of two adults and two children who sometimes dry clothes indoors.

\section{$4 \quad$ Thermal modelling}

Condensation Targeter II requires a thermal model to predict the internal temperature. The internal temperature is determined by the heat loss of the building, the type of heating system, its control and other sources of internal heat gain. The most difficult to predict is the heating system control. Even if the heating system is adequately sized and in theory can be controlled to maintain comfortable conditions, occupants may chose to maintain conditions below comfort in order to make heating costs affordable. For this reason, a key input into Targeter is the annual fuel expenditure; this along 
with the heating system efficiency and fabric data is used to determine the mean internal temperature. Bredem has shown itself to be one of the most reliable thermal models for predicting the energy costs of a dwelling ${ }^{(23-26)}$ and so has been incorporated into Targeter to predict the mean internal temperature. Several versions of Bredem are now available. This paper examines the use of Bredem-12(34) which calculates a seasonal average internal temperature and uses modified heating season degree days to characterise the external climate and Bredem $-8^{(35)}$ which predicts mean monthly energy consumption and temperatures from mean external temperature and solar radiation.

\section{$5 \quad$ Moisture modelling}

Condensation Targeter II requires a moisture model to predict the internal vapour pressure which when combined with the temperature can be used along with psychrometric data to predict both the monthly airspace and surface relative humidity. Moisture movement through a building is far more complex to predict than is heat. Many of the mechanisms by which moisture moves through the building fabric are poorly understood or the material properties, which influence this movement, are often poorly characterised. Figure 4 shows the typical moisture flows in a dwelling. The majority of moisture is carried directly by ventilation. Therefore, the simplest approach is to assume that moisture transfer only occurs through bulk air movement

between inside and outside the building, as first proposed by Loudon ${ }^{(27)}$. In other words this approach ignores diffusion through the fabric and hygroscopic adsorption/desorption. 
Loudon's steady state moisture model equation is shown below:

$$
\bar{\psi}_{i}=\bar{\psi}_{o}+\frac{\bar{G}}{n \rho v}
$$

BS5250 simplifies the above to predict vapour pressure for conditions typically found in dwellings:

$p_{i}=p_{o}+\frac{C}{0.191 \cdot n \cdot v}$

Because of the relatively high vapour resistivity of most building fabrics diffusion is a negligible factor accounting for approximately $1 \%$ of the moisture transferred by bulk air movement. The hygroscopic impact is far more difficult to predict and several attempts have been made to find simple methods of characterising the hygroscopic impact of the fabric and furnishings ${ }^{(29,31,32)}$. Without doubt, over short time periods hygroscopic properties can play a major role in dampening down the variations associated with high moisture production. For example, the peak excess water vapour content of a kitchen during a short cooking period is one third the value that theoretically would be expected if there were no hygroscopic materials ${ }^{(28)}$. On a daily cycle it has been estimated that only the first $10 \mathrm{~mm}$ of fabric is normally involved in moisture transfer. The surface layer responsible for the hygric storage for daily swings in the indoor air humidity is very small. The corresponding thickness for temperature swings is about $100 \mathrm{~mm}^{(30)}$. If one assumes that the greatest swing in relative humidity from one day to another is $30 \%$ and the surface area of hygroscopic fabric is $200 \mathrm{~m}^{2}$ 
then over the day some $6 \mathrm{~kg}$ of moisture will move between the air and the fabric. However, such a large swing is only likely to take place on a few days in the year such as at the end of summer when the heating system is turned on.

Jones has proposed a moisture admittance equation that defines two admittance coefficients, $\alpha$ and $\beta$ which account for the moisture adsorption and desorption within the dwelling. Jones has suggested that the following equation 'should be included in all but the most simple models ${ }^{\prime(31)}$. He continues, 'In the Bredem energy model which includes vapour pressure calculations, the Loudon steady-state equation could be amended to':

$\bar{\psi}_{i}=\frac{n \bar{\psi}_{o}+\left(\bar{G} / \rho v+\beta \bar{\psi}_{s v p}\right)}{n+\alpha}$

Converting the vapour content terms in the equation to vapour pressures gives:

$p_{i}=\frac{\left(0.0062 . n \cdot p_{o}+\left(C / 28.8 \cdot v+0.0062 \cdot \beta \cdot p_{s v p}\right)\right)}{0.0062(n+\alpha)}$

Typical values for $\alpha$ and $\beta$ for a wood lined room have been put forward by Jones as $\alpha=0.6$ and $\beta=0.4$. Jones further suggests that numbers of this order could be expected to apply to normal types of buildings. Another study ${ }^{(32)}$ has measured coefficients in a furnished dwellings with similar coefficients, $\alpha=0.72$ and $\beta=0.47$. 
This paper investigates both the Loudon and Jones moisture models by comparing their predictions against measured data.

\section{Condensation Targeter II}

Based on the above modifications, which are graphically represented in Figure 1, Condensation Targeter II was implemented into an Excel spreadsheet. Four different versions of the spreadsheet were produced to assess the impact of monthly calculations and Loudon's moisture model compared to Jones. These are indicated in Table 2.

\begin{tabular}{|c|c|c|}
\hline Version & Moisture model & Thermal model \\
\hline 1 & Loudon & Bredem- 8 \\
\hline 2 & Loudon & Bredem-12 \\
\hline 3 & Jones & Bredem- 8 \\
\hline 4 & Jones & Bredem-12 \\
\hline
\end{tabular}

Table 2 - Different versions of Condensation Targeter II

The Bredem-12 annual and Bredem- 8 monthly models were checked against a BRE version of Bredem- $8^{(35)}$ and a NES Limited version of Bredem-12 $2^{(34)}$ and after elimination of small inconsistencies in the programs and the written Bredem documentation, both shown to have excellent agreement.

\subsection{Monitored versus modelled data}


The predictions of the four versions of Condensation Targeter II have been compared against monitored data for 36 dwellings collected over a heating season. The 36 dwellings consist of 29 modern well-insulated dwellings, ranging from 1 bedroom flats to 5 bedroom houses, located at the Milton Keynes Energy Park (MKEP) and monitored from October 1989 to May 1990 by the National Energy Foundation, and seven older largely uninsulated dwellings in Southwest London monitored by the authors from October 1997 to May 1998. Dwellings located at both sites had temperature and relative humidity data recorded at hourly intervals and external conditions monitored at a local weather station. Occupant interviews and social surveys were carried out to obtain information regarding the use of the building. Data regarding the construction and dimensions was also collected. Ideally, a comparison between monitored and predicted surface relative humidity should be carried out. However, no such data is available over a heating season for several dwellings. Also, data from a greater number of dwellings with high relative humidity would ideally have been incorporated.

Figure 5 shows monitored relative humidity for one of the MKEP dwellings from July 1988 to September 1990. During the heating season of October 1989 to May 1990, the relative humidity is high at the commencement of the heating season and progressively reduces until the end. This is typical of the data collected at MKEP and in Southwest London. The very high levels of relative humidity at the commencement of the monitoring period (1988) are due to the drying out of the new dwelling, which was constructed just before monitoring started. 
From the monitored data the monthly and seasonal temperature and relative humidity have been calculated and compared with Condensation Targeter II predictions of the internal relative humidity and temperature using 'real' fabric data, occupant profiles and external monitored weather data as inputs.

The Version 1 and 3 predictions are compared against each of the eight months October to May, whilst the Version 2 and 4 results are compared against seasonal averages. Figure 6 shows the results of the Version 2 and 4 seasonal average comparisons. A linear trend-line has been included for both the Loudon and Jones moisture models. Ideally, the trend-line would coincide with the $\mathrm{y}=\mathrm{x}$ line which has also been plotted as a dotted line. Figure 7 shows the relative humidity results for the monthly Version 1 and 3 models.

In both cases, using Loudon's moisture model, $65 \%$ of the relative humidity results are within $\pm 5 \%$ of the monitored relative humidity, whilst $95 \%$ of the results are within $\pm 10 \%$. The results indicate that relative humidity predictions are overestimated at low relative humidities and under-estimated at high relative humidities. For seasonal and monthly predictions of relative humidity the steady state moisture model proposed by Loudon shows better agreement with the monitored data than the admittance model proposed by Jones. It is thought that this is because the Jones admittance model is more appropriate for use in a transient situation where changes in relative humidity are determined over time periods considerably shorter than monthly or seasonal periods. 


\subsection{Use of the model}

Version 1 of Condensation Targeter II has been used to predict the risk of mould growth in a typical 1996 building regulations semi-detached house with typical properties indicated in Table 3.

\begin{tabular}{|l|l|}
\hline Specific Heat Loss & $132 \mathrm{~W} \mathrm{~K}^{-1}$ \\
\hline Wall U-value & $0.45 \mathrm{Wm}^{-2} \mathrm{~K}^{-1}$ \\
\hline Window U-value & $2.80 \mathrm{Wm}^{-2} \mathrm{~K}^{-1}$ \\
\hline Floor U-value & $0.40 \mathrm{Wm}^{-2} \mathrm{~K}^{-1}$ \\
\hline Roof U-value & $0.25 \mathrm{Wm}^{-2} \mathrm{~K}^{-1}$ \\
\hline Air change rate & $0.65 \mathrm{ach}^{-1}$ \\
\hline Volume & $200 \mathrm{~m}^{2}$ \\
\hline Moisture production rate & $7.26 \mathrm{~kg} \mathrm{day}^{-1}$ \\
\hline Number of occupants & $4(2$ adults and 2 children $)$ \\
\hline Heating system specification & Gas boiler with fan-assisted flue \\
\hline
\end{tabular}

Table 3 - Description of a 1996 Building Regulations semi-detached house

\subsection{Seasonal variations}

The monthly variations in relative humidity predicted using the Version 1 model with a fixed internal demand temperature and ventilation rate are indicated in Figure 8. This indicates that the critical period for relative humidity in this dwelling occurs very early in the heating season. The general trend of relative humidity between October and May, the heating season normally assumed, shows that relative humidity is highest at the start of this season and reduces gradually as the season progresses, which is reflected in the monitored data results described earlier. Outside the heating 
season the predicted conditions may be less accurate due to varying internal temperatures and ventilation rates.

The Bredem- 8 predictions show that the highest relative humidity occurs on the window and cold bridge surfaces in both zones. Ignoring these surfaces, since the former is not a problem until condensation occurs and the latter should not occur in properly designed and constructed dwellings, the variation in relative humidity between the surface and air for any particular month is low. In modern well-insulated dwellings, such as that indicated in Table 3, without cold bridges, the difference between airspace relative humidity and surface relative humidity for a particular zone is significantly less than the $10 \%$ difference assumed by BS 5250 . This is due to the warmer internal surfaces of well-insulated dwellings. The most critical period appears to be October for both air and surface relative humidity.

By modelling the same dwelling using U-values appropriate to a traditional dwelling it can be shown that the difference between surface relative humidity and airspace relative humidity is significantly greater than in well-insulated dwellings. The average difference between the wall surface relative humidity and the airspace relative humidity in a well-insulated dwelling over the heating season is $2 \%$. For the traditional poorly insulated dwelling the difference is $10 \%$. For severe cold bridges there may be a $20 \%$ difference in relative humidity between the cold bridge and the air, the difference being greatest in the winter. This coincides with the 'at risk' period recommended in BS 5250 . 


\subsection{Regional Variations}

Regional variations are known to cause a difference in the risk of mould growth. However, it is reported in the latest English Housing Condition Survey ${ }^{(1)}$ that the variation of the incidence of condensation and mould growth in different UK regions is not marked, ranging from $19 \%$ of dwellings with some form of problem in Outer London to $29 \%$ in the West Midlands. Although the four least affected regions are all in the south east of England, with a relatively mild climate and little exposure to driving rain, this geographical and climatic pattern is not reflected in other UK regions. It is stated that the age of the dwelling stock, the provision of central heating and the overall affluence of the region are more important factors.

Condensation Targeter can assist in the interpretation of English House Condition Survey data in a similar manner to the way that Bredem can help interpret energy statistics as it is able to model dwellings in any one of $21 \mathrm{UK}$ regions.

Using data for a traditional semi-detached house, with solid brick walls and single glazing, the Version 1 model has been used to determine the effect of geographical region on the internal relative humidity. Figure 9 indicates the effect of geographical region on critical relative humidity. Ignoring cold bridges, the critical periods are those where airspace humidity exceeds $70 \%$ or where surface relative humidity exceeds $80 \%$. A similar study carried out for a modern semi-detached dwelling identified no critical relative humidity periods for any of the geographical locations modelled. 
Critical relative humidity generally occurs early in the heating season or before it starts. In addition to this, generally, the further North a dwelling is located the earlier in the year that critical relative humidity occurs and for a longer period. The only difference between the results for each region is the data input for the external climate. Future analysis will include regional variations in building stock as well as climate in order to compare predictions with English House Condition Survey data. Also, ventilation rates are likely to change outside the heating period due to higher window opening which needs to be further studied.

\subsection{Sensitivity Analysis}

Figure 10 shows the sensitivity of airspace relative humidity predictions by Version 1 of Condensation Targeter II to changes in input data. Each parameter has been varied across the typical range found in UK dwellings while all other parameters have been kept constant. Surprisingly, the most significant input parameter is the heating pattern. A change in the heating pattern from a 5-hour evening only pattern to an extended 16hour heating pattern causes a reduction in relative humidity of $23 \%$. This has an important impact on the affordability of heating in dwellings and the effect of heating pattern on condensation and mould growth. The next most significant input parameter is the dwelling occupancy, which has a significant impact on the Bredem algorithm and has an important impact on most of the moisture production calculations. A change from 2 to 6 occupants results in a change in internal relative humidity of $14 \%$. The third most significant input parameter is the ventilation rate of the dwelling. Using Bredem to model the highest and lowest possible ventilation rates in the 
dwelling, with air change rates of 2.8 ach and 0.57 ach respectively, a change in internal relative humidity of just under $14 \%$ occurs. Other input parameters which have a significant effect on internal relative humidity predictions include the demand temperature, the geographical location of the dwelling, the thermal properties of the dwelling fabric, drying clothes indoors, the use of unvented secondary heating systems and the location of the kitchen in the dwelling. Similar results apply to surface relative humidities with the one exception that changes in U-value have a greater impact for reasons already covered in section 3.2.

\section{$7 \quad$ Discussion and future work}

Several of the limitations of Condensation Targeter I have been addressed in this paper. The revised model, Condensation Targeter II, incorporates a monthly calculation to investigate when the critical conditions occur, it determines conditions at the dwelling surfaces, including cold bridges, and it allows seasonal variations in the ventilation rate to be examined.

Condensation Targeter II allows the impact of key variables associated with mould growth, such as fabric type, ventilation, heating system, occupant fuel affordability and occupant density, to be assessed in order that the impact of design and policy decisions can be tested. Comparison between monitored and predicted data for the Version 1 model shows good agreement ( $65 \%$ of the relative humidity results within \pm $5 \%, 95 \%$ of the results within $\pm 10 \%$ ) when a monthly, steady state model is used. Because the model can predict the impact of climatic variations on a monthly basis, both regional and seasonal variations can be studied. The most critical period for 
mould growth assuming a similar ventilation rate throughout the heating season appears to be the autumn and not, as often assumed, the winter period. This is due to higher external vapour pressures in autumn being a more dominant factor than the colder winter surface temperatures. The further North a dwelling is located the earlier, and for longer, in the year is the critical period for mould growth. Of the $21 \mathrm{UK}$ regions the most at risk from mould growth are the Border regions, Shetland Isles and West Scotland. The least at risk are the Thames Valley region, the South and the Southwest. This suggests that the key factors in determining the early onset of mould growth may be how the building is ventilated in the autumn period and when an occupant decides to turn on the heating. Although a relative humidity of $70 \%$ is often taken as critical for mould growth, any construction with a cold bridge resulting in a Temperature Difference Ratio of 0.15 or higher, for example a solid brick wall, is at risk from mould growth at lower relative humidities.

Condensation Targeter highlights the importance of issues other than ventilation, which may play a significant role in determining mould growth. In particular, occupant density, insulation, fuel poverty and occupant-set heating patterns play a critical role. Some of these factors may appear to be more the responsibility of housing policy than housing design. However, issues such as fuel poverty and moisture production are affected to some degree by housing design. For example, the fabric and heating system must be designed to minimise energy costs and moisture production will be high if the design of the building does not provide suitable facilities to dry clothes and remove moisture at sources of high production. Often such decisions are the responsibility of several different housing professionals. For example, communal drying facilities may be abandoned by the facility manager of a 
Local Authority in order to save funds but can result in extra maintenance expenditure. It is hoped that Condensation Targeter II will provide a structured vehicle by which a more holistic approach can be taken to assessing the risk of mould growth in dwellings.

Software based on Condensation Targeter I has been used in court cases where there is a dispute about the cause of mould growth. These normally centre on resolving whether the tenant is producing too much moisture or whether the fabric and services are to blame. This is clearly an issue on which Condensation Targeter II can provide quantifiable evidence. However, care must be taken when using such tools that account is taken of all the underlying assumptions. The main benefit such a tool can provide is to assess whether mould growth is likely if a 'typical' occupant were to inhabit the property. In fact, tools such as Targeter and Bredem cannot predict what a particular occupant will do in their building. What's more, there is little practical point in modelling an existing dwelling with a specific occupant other than for purposes of research. Reality will always be a better model than any computer model. It is therefore far better to monitor what is happening rather than try to model it. The other application of a model such as Condensation Targeter II is to predict what may happen as a result of carrying out an intervention or in the design of a new building not yet constructed. Condensation Targeter II only models average conditions and not peak conditions, as discussed previously. If under average conditions there is a problem, then peak conditions will make the situation worse. However, if for example under average conditions there is no indication of condensation, Condensation Targeter II cannot show that there is no risk during peak conditions. Therefore, 
Condensation Targeter II can only indicate that you might expect mould growth due to poor fabric and/or services but never that the tenants use is inappropriate.

\section{Acknowledgements}

The Milton Keynes Energy Park (MKEP) monitored data was collected as part of a study carried out for the BRE by the National Energy Foundation (NEF), with the financial support of the Energy Efficiency Office (EEO).

For the use of the MKEP and other data and for assistance in validating the Bredem models thanks are due to Brian Anderson, Chris Sanders and Les Shorrock at the BRE.

For advice and assistance in the interpretation of the collected data and validation of the Bredem-12 model thanks are due to Neil Cutland, Alan Horton and Paul Wolfe at NES Limited.

Thanks are also due to Roger Critchley for his useful comments during the drafting of this paper.

\section{References}

1. Department of the Environment English Housing Condition Survey 1991: Energy Report (HMSO) (1996) 
2. International Energy Agency (IEA) Annex 14: Condensation and Energy: Volume 1: Sourcebook (IEA) (1991)

3. Medical Research Council / Institute for Environment and Health IEH assessment on Indoor Air Quality in the home: Assessment A2 (MRC/IEH) (1998)

4. Raw G J, Hamilton R M (editors) Building Regulation and Health (Building Research Establishment) (1995)

5. Trechsel H R Moisture Control in Buildings American Society for Testing and Materials (ASTM) manual 18 (ASTM) (1994)

6. Rowan et al Development of a computer programme for the prediction and control of mould growth in buildings using the ESP-r modelling system Indoor Built Environment (6) 4 - 11 (1997)

7. Boyd D, Cooper P, Oreszczyn T Condensation risk prediction: addition of a condensation model to BREDEM Building Services Engineering Research and Technology 9 (3) 117 - 125 (1988)

8. Oreszczyn T, Boyd D, Cooper P Condensation Targeter: The integration of a thermal and moisture model Proceedings of Building Simulation 1989, June 23 24, 1989, Vancouver, Canada (1989)

9. Critchley R Condensation and energy audits: a misleading mismatch, Energy Action, 70, November 1997, p16-18.

10. Brundrett G W Criteria for Moisture Control Butterworths (1990)

11. Grant C, Hunter C A, Flannigan B, Bravery A F The moisture requirements of moulds isolated from domestic dwellings International Biodeterioration 25259 284 (1989) 
12. Sanders C International Energy Agency (IEA) Annex 24: Heat, Air and Moisture Transfer in Insulated Envelope Parts: Volume 2: Environmental Conditions (IEA) (1996)

13. Cunningham M J Controlling Dust Mites Psychrometrically - a Review for Building Scientists and Engineers Indoor Air (6) 249-258 (1996)

14. Oreszczyn T Insulating the existing housing stock: mould growth and cold bridging in Roaf S (Editor) Energy Efficiency in Buildings (1994)

15. Brundrett G Window opening in houses: an estimate of the reasons and magnitude of the energy waste Electricity Council Research Centre ECRC/M801, March (1975)

16. Draft European Standard CEN/TC89 WI29: Hygrothermal performance of building components and building elements - Estimation of internal surface temperature to avoid critical surface humidity and calculation of interstitial condensation (CEN) (1997)

17. Chartered Institution of Building Services Engineers (CIBSE) CIBSE Guide Volume A10: Moisture Transfer and condensation (CIBSE) (1986)

18. British Standards Institute (BSI) BS 5250: 1989 Control of Condensation in Buildings (1989)

19. Angell W J, Olson W W Moisture sources associated with potential damage in cold climate housing Cold Climate Housing Information Centre, University of Minnesota (1988)

20. Garratt J, Nowak F Tackling condensation Building Research Establishment Report (1991)

21. Stum K R Winter steady-state relative humidity and moisture load predictions in dwellings ASHRAE Transactions Volume 98 Part 1 (1992) 
22. Finbow M Avoiding condensation and mould growth in existing housing with the minimum energy input Third AIC Conference, September 20 - 23 London (1982)

23. Henderson G, Shorrock L D BREDEM - The BRE domestic energy model: Testing the predictions of a two zone model Building Services Engineering Research and Technology 7 (2) 87 - 91 (1986)

24. Shorrock L D, Dunster J E, Seale C F, Eppel H, Lomas K J Testing Bredem-8 against measured consumption data and against simulation models Proc. BEPAC Conf. Building Environmental Performance '94 (1994)

25. Shorrock L D, Macmillan S, Clarke J, Moore G Bredem-8, a monthly calculation method for energy use in dwellings: Testing and Development Proc. BEPAC Conf. Building Environmental Performance '91 (1991)

26. Shorrock L D, Anderson B R A guide to the development of BREDEM BRE Information Paper IP 4/95 (1995)

27. Loudon A G The effects of ventilation and building design factors on the risk of condensation and mould growth in dwellings Building Research Station Current Paper CP 31/71 (1971)

28. Shepherd T, Parkins L, Cripps A Effects of passive and mechanical ventilation on kitchen moisture levels Proc. CIBSE National Conference (1994)

29. Boot J L C L The hygroscopic buffer capacities of fixtures and fittings International CIB W67 Symposium, 'Energy, Moisture and Climate in Buildings' September 3 - 6, Rotterdam (1990)

30. Wit M H, Donza G J A model for the prediction of indoor air humidity International CIB W67 Symposium, 'Energy, Moisture and Climate in Buildings' September 3 - 6, Rotterdam (1990) 
31. Jones R Modelling water vapour conditions in buildings Building Services Engineering Research and Technology 14 (3) 99 - 106 (1993)

32. Serive-Mattei L, Jones R, Kolokotroni M, Littler J Moisture admittance model: Measurements in a furnished dwelling Proc. $14^{\text {th }}$ AIVC Conference $21-23$ September, Denmark (1993)

33. HMSO Averages and frequency distributions of humidity for Great Britain and Northern Ireland 1961 - 70 Meteorological Office, Climatological Memorandum $103(1976)$

34. Anderson B R, Chapman P F, Cutland N G, Dickson C M, Shorrock L D, BREDEM-12 Model Description Building Research Establishment (1996)

35. Anderson B R, Chapman P F, Cutland N G, Dickson C M, Doran S M, Iles P J, Shorrock L D, BREDEM-8 Model Description Building Research Establishment (1997)

36. Evaluator, National Energy Services Ltd, Rockingham Drive, Linford Wood, Milton Keynes, MK14 6EG.

37. Oreszczyn T and Littler J Cold Bridging and Mould Growth, SERC final report Research in Building, University of Westminster, 35 Marylebone Road, London NW1 5LS.

38. Building Research Establishment Conservation Support Unit, Minimising thermal bridging in new dwellings - a detailed guide for architects and building designers BRECSU Good Practice Guide 174, DOE, London (1996).

39. Building Research Establishment Conservation Support Unit, Minimising thermal bridging when upgrading existing housing - a detailed guide for architects and building designers BRECSU Good Practice Guide 183, DOE, London (1996). 
40. Adan O C G On the fungal defacement of interior finishes $\mathrm{PhD}$ thesis, Netherlands Organisation for Applied Scientific Research (TNO), Denmark, (1994). 